\title{
Mechanical testing of thin-walled zirconia abutments
}

\author{
Luigi CANULLO', Paulo G. COELHO ${ }^{2,3}$, Estevam A. BONFANTE ${ }^{4}$
}

\begin{abstract}
1- DDS, Private Practice, Rome, Italy.
2- DDS, MS, BS, MsMtE, PhD, Assistant Professor, Department of Biomaterials and Biomimetics, New York University College of Dentistry, New York, USA.

3- Director for Research - Department of Periodontology and Implant Dentistry, New York University College of Dentistry, New York, USA.

4- DDS, MS, PhD, Assistant Professor, Postgraduate Program in Dentistry, School of Health Sciences, UNIGRANRIO University, Duque de Caxias, RJ, Brazil.
\end{abstract}

Corresponding address: Estevam Augusto Bonfante - Rua Prof. José de Souza Herdy, 1.160 - 25 de Agosto - Duque de Caxias, RJ, Brazil, $25071-202$ Phone: 55 (14) 8153-0860 - Fax: 55(14) 3234-2566 - estevamab@gmail.com

Submitted: February 9, 2012 - Modified: December 17, 2012 - Accepted: December 20, 2012

\section{ABSTRACT}

\begin{abstract}
$A^{\prime}$ Ithough the use of zirconia abutments for implant-supported restorations has gained momentum with the increasing demand for esthetics, little informed design rationale has been developed to characterize their fatigue behavior under different clinical scenarios. However, to prevent the zirconia from fracturing, the use of a titanium connection in bicomponent aesthetic abutments has been suggested. Objective: Mechanical testing of customized thin-walled titanium-zirconia abutments at the connection with the implant was performed in order to characterize the fatigue behavior and the failure modes for straight and angled abutments. Material and Methods: Twenty custom-made bi-component abutments were tested according to ISO 14801:2007 either at a straight or a $25^{\circ}$ angle inclination ( $n=10$ each group). Fatigue was conducted at $15 \mathrm{~Hz}$ for 5 million cycles in dry conditions at $20^{\circ} \mathrm{C} \pm 5^{\circ} \mathrm{C}$. Mean values and standard deviations were calculated for each group. All comparisons were performed by t-tests assuming unequal variances. The level of statistical significance was set at $p \leq 0.05$. Failed samples were inspected in a polarizedlight and then in a scanning electron microscope. Results: Straight and angled abutments mean maximum load was $296.7 \mathrm{~N}$ and 1,145 N, the dynamic loading mean Fmax was 237.4 $\mathrm{N}$ and $240.7 \mathrm{~N}$, respectively. No significant differences resulted between the straight and angled bi-component abutments in both static $(p=0.253)$ and dynamic testing $(p=0.135)$. A significant difference in the bending moment required for fracture was detected between the groups $(p=0.01)$. Fractures in the angled group occurred mainly at the point of load application, whereas in the straight abutments, fractures were located coronally and close to the thinly designed areas at the cervical region. Conclusion: Angled or straight thinwalled zirconia abutments presented similar $\mathrm{F}^{\mathrm{max}}$ under fatigue testing despite the different bending moments required for fracture. The main implication is that although zirconia angled or straight abutments presented similar mechanical behavior, the failure mode tended to be more catastrophic in straight (fracture at the cervical region) compared to angled abutments.
\end{abstract}

Key words: Dental implants. Zirconium. Dental implant-abutment design. Fatigue

\section{INTRODUCTION}

Since osseointegration became a safe treatment modality in dentistry, several designs of implantabutment systems have been available for clinical use, with a plethora of data being produced on titanium as the main abutment material. Historically, the external hexagon connection was designed to provide an engagement method for implant placement and anti-rotational feature for single-unit prosthesis, and is likely the functioning system with the longest clinical follow-up 15,20,21. Despite the high survival rates of titanium abutments, the esthetic outcome should also be considered as a success factor, especially in the anterior esthetic zone. Key elements to be considered include: height of the smile line, gingival biotype, color of the neighboring teeth and the esthetic expectations of the patient ${ }^{19}$. 
In essence, implant abutments can be made of ceramic (yttrium tetragona zirconia polycristals, i.e. Y-TZP) or titanium (commercially pure or alloyed) and can also be prefabricated or customized. The standardization of the prefabricated abutments may present a limitation to the establishment of an appropriate emergence profile, especially in cases where a discrepancy exists between the implant and the crown diameter. In such cases, the compensation will be made by the final contour of the crown, which could result in unfavorable core/ porcelain thickness ratios. A way to overcome this issue is the use of a customized abutment that will allow for an individual emergence profile forthrightly by the abutment instead of the crown ${ }^{13}$.

Customized-zirconia abutments have shown comparable survival rates relative to titanium abutments ${ }^{17,22}$.

However, the internal connection between a zirconia customized abutment and the implant continues to be a mechanical challenge. Thus, to prevent the zirconia from fracturing at the connection, the use of a titanium connection in bi-component aesthetic abutments have been suggested ${ }^{2}$.

Among the concerns regarding the use of CAD/CAM customized-zirconia abutments is their unknown mechanical performance in clinical situations where the implant positioning and occlusal restraints result in thin abutment walls that may negatively influence the long-term prosthetic functional outcome ${ }^{3}$. Although the buccolingual positioning and angulation of the implant is crucial for the final prosthetic outcome, oftentimes there is a need to compensate non-ideal implant positioning with angled customized abutments. Whereas, the mechanical property of customized titanium abutments may be less affected by the resulting wall thinning, due to its ductile nature, the same assumption may not hold true for brittle ceramic abutments. Therefore, this study evaluated the mechanical performance of thinned zirconia abutments at the connection, in an attempt to simulate 2 implantation scenarios in terms of inclination. In fact, in the anterior aesthetic zone, according to the different available bone conditions, implant insertion may require straight (mostly in canine and bicuspid zones) or inclined (incisor zones) abutments.

The tested null hypothesis was that a straight bi-component abutment does not present a different fatigue life compared to an angled one.

\section{MATERIAL AND METHODS}

Twenty custom-made zirconia abutments (Sweden \& Martina, Padua, Italy) were tested according to Norm UNI EN ISO 14801:2007
(Dynamic fatigue test of endosseous dental implants) either with a straight inclination $(n=10)$ or a $25^{\circ}$ angle relative to the implant long axis $(n=10)$ (Figures $1 A$ and $B)$. In order to evaluate the abutments under a worst case scenario, an industrially imposed minimum thickness of $0.3 \mathrm{~mm}$ at the connection area with the implant was chosen.

The implant fixture was inserted in a prefabricated rigid Plexiglas ${ }^{\circledR}$ clamping device. Individualized zirconia abutments were cemented on a titanium connection and fixed to the implant using a titanium screw according to the manufacturer's instructions: after cleaning with alcohol, the zirconia abutment was cemented onto the titanium connection (All Stone cement, Sweden \& Martina, Padua, Italy). The mixed cement was applied onto the contact part of the titanium connection. The zirconia abutment was then fit onto the titanium connection. The remaining cement was removed immediately with steam and after polymerization, the excess cement was removed.

A PEEK (polyetherketone) ring was used for stress distribution at the zirconia/titanium interface interposed between the zirconia abutment and

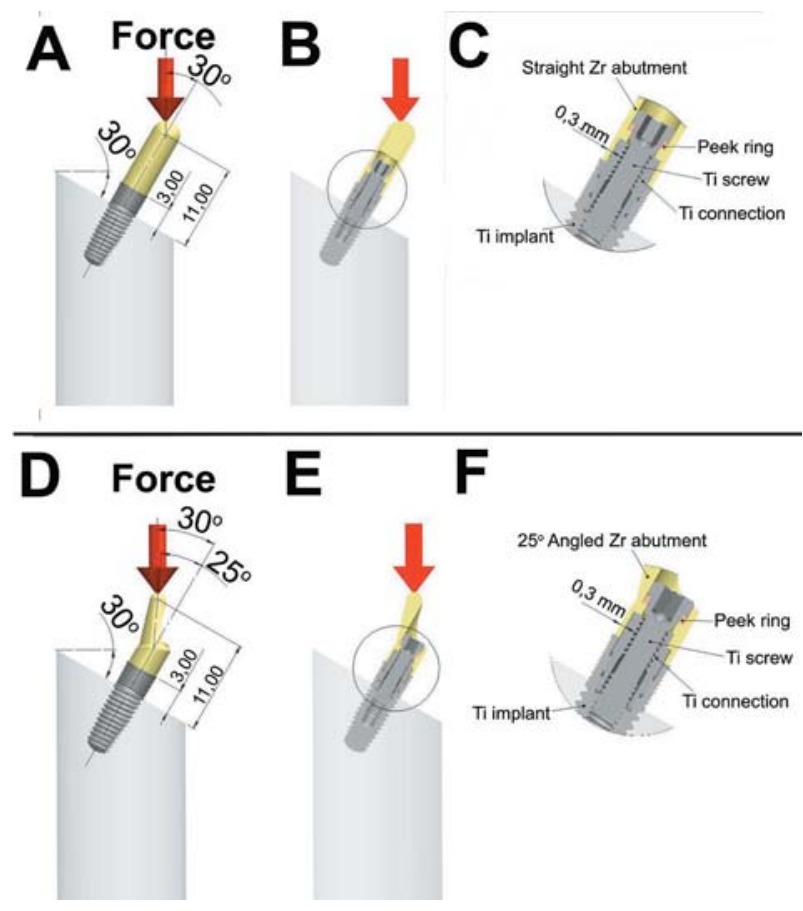

Figure 1- Testing configuration for the A) straight zirconia $(\mathrm{Zr})$ abutment showing the distances between the abutment assembly and the potting surface and B) the $30^{\circ}$ loading orientation. The area circled in $\mathrm{B}$ is magnified in C) where the component parts are described and the circumferential $0.3 \mathrm{~mm}$ thicknesses of the zirconia abutment at the connection is depicted. The same patterns regarding the $\mathrm{D}$ ) distance of the abutment assembly and E) loading orientation are observed in the $25^{\circ}$ angled abutment groups. Components and thicknesses circled in $E$ are described in magnified figure $F$ 
retaining screw (Figure 2).

For mechanical testing, single load to fracture (SLF) was performed (6027, Instron, USA) $(n=10$ each), and the mean values were used to calculate the maximum load $\left(\mathrm{F}_{\max }\right)$. The loading geometry was fixed by UNI EN ISO 14801:2007 both for the SLF and dynamic loading tests. The implant/ abutment system was positioned with its long axis inclined at a $30^{\circ} \pm 1^{\circ}$ angle relative to the loading direction. The dimensions of the indenter resulted in a distance of $I=11.0 \mathrm{~mm} \pm 0.1 \mathrm{~mm}$ from the center of the hemisphere to the clamping plane (Figure 3a).

A hemispherical indenter was used for the load application. Eighty percent of the $F_{\max }$ was used as a starting load value for the dynamic testing, which used an uni-axial testing equipment (FPF, Italsigma, Italy), with a $2.000 \mathrm{~N}$ load cell (TSTM, AeP, Italy) and an extensometer (2620-601, Instrom, USA) (Figure $3 \mathrm{~b}$ ). Fatigue was conducted at $15 \mathrm{~Hz}$ for 5 million cycles in dry conditions at $20^{\circ} \mathrm{C} \pm 5^{\circ} \mathrm{C}$. The bending moment was calculated as follows:

$$
M=y \times F
$$

where $y$ is the moment arm (defined by I $x$ sin $30^{\circ}$ ), and $\mathrm{F}$ is the force expressed in newtons.
Failed samples were inspected in a polarized-light microscope (MZ-APO, Carl Zeiss Micro Imaging, Thornwood, NY, USA) and then in a scanning electron microscope at an acceleration voltage of $10 \mathrm{Kv}\left(\mathrm{XVP}^{\circledR}{ }^{\circledR}\right.$, Evo 50, Carls Zeiss AG, Oberkochen, Germany).

\section{Statistical analysis}

Mean values and standard deviations were calculated for each outcome variable (static and dynamic tests) as a function of the straight and inclined abutment groups.

All comparisons were performed by t-test assuming unequal variances [SigmaStat 3.0 (SPSS Inc., Chicago, IL, USA)]. The level of statistical significance was set at $p \leq 0.05$.

\section{RESULTS}

The mean $F_{\max }$ value for SLF, dynamic loading are presented in Table 1 , as well as the bending moments required for fracture.

No significant differences in load to failure were observed between the straight and angled bi-

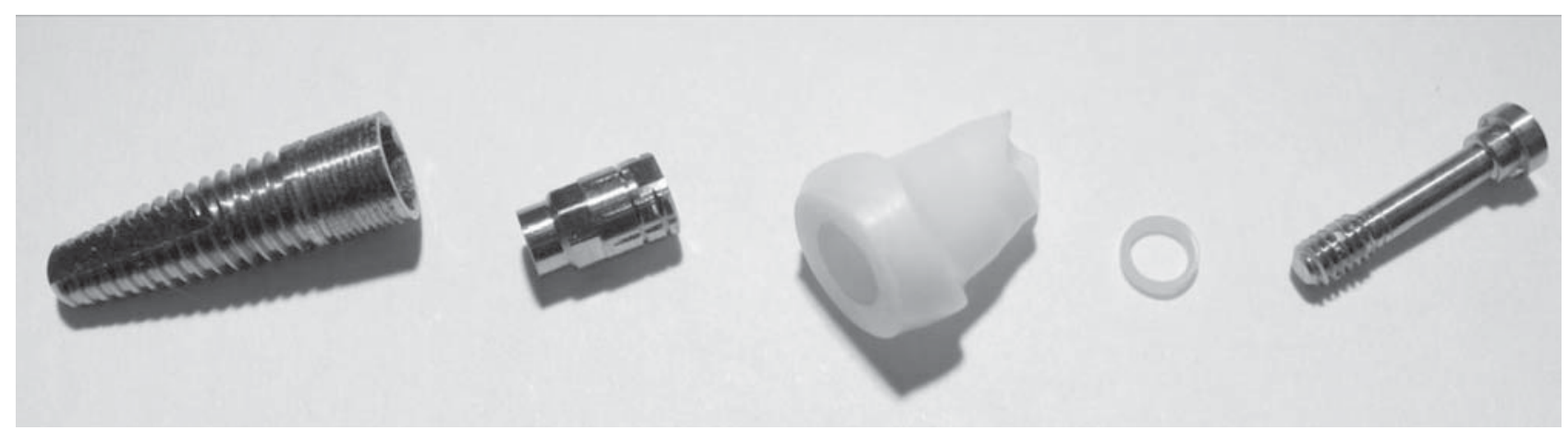

Figure 2- Components of the custom-made abutment composed by an individualized zirconia abutment cemented on a titanium connection linked to the implant using a titanium screw. A peek ring was used for stress distribution at the zirconia/ titanium interface interposed between the zirconia abutment and retaining screw

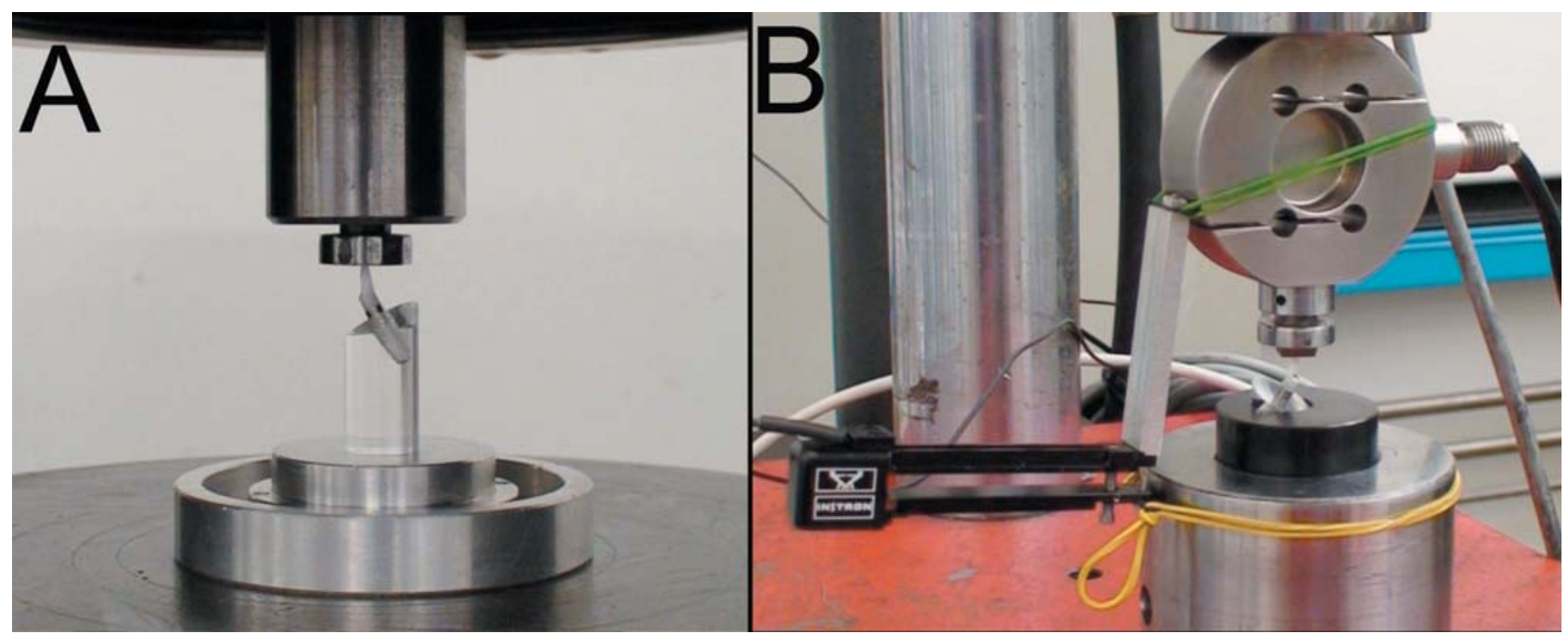

Figure 3- (A) Single load to fracture (SLF) and (B) dynamic loading testing machines 
Table 1- Mean values for mechanical testing of the straight and $25^{\circ}$ angled zirconia abutment groups

\begin{tabular}{lccc}
\hline & $\begin{array}{c}\text { STATIC } \\
\text { Mean (N) (SD) }\end{array}$ & ${\text { DYNAMIC } \text { F }_{\text {max }} \text { (N) }}$ & $\begin{array}{c}\text { BENDING MOMENT } \\
\text { Mean (Nmm) (SD) }\end{array}$ \\
\hline STRAIGHT & $296.7(34.42)$ & 237.4 & $690.6(60)$ \\
$25^{\circ}$ ANGLED & $1145(30.69)$ & 240.7 & $410.5(5.45)$ \\
\hline
\end{tabular}

SD: Standard Deviation

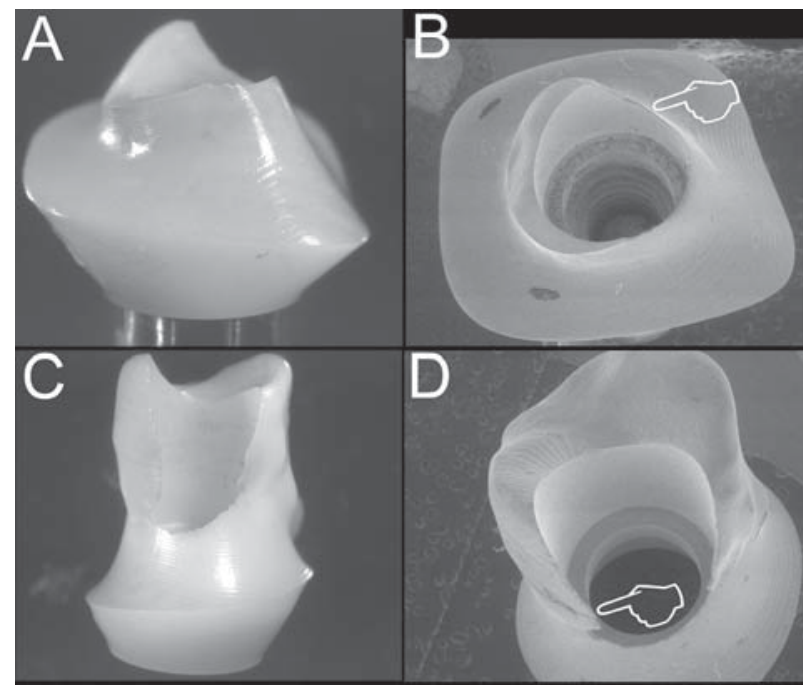

Figure 4- Representative polarized light and scanning electron microscope micrographs of abutment samples failed during fatigue. A) Straight abutment group in a frontal view depicting that fractures occurred coronally at B) thinly designed areas (pointer) mostly close to the base of the abutment, as observed in this occlusal view. C) In the angled group, fracture occurred at the point of load application involving D) thinly designed areas (pointer), as observed in this occlusal view

component abutments in both the static $(p=0.253)$ and dynamic tests $(p=0.135)$. A significant difference in the bending moment required for fracture was detected between the groups $(p=0.01)$.

Fractures in the angled group occurred chiefly at the point of load application, whereas in the straight abutments fractures were located coronally and close to the thinly designed areas at the cervical region (Figure 4 ).

\section{DISCUSSION}

The present study simulated clinical scenarios where customized zirconia abutments presented the thinnest possible section at the connection area, resulting in significant implications in its mechanical response, according to our SLF testing. However, when evaluated under a more clinically realistic loading scenario, (fatigue) $F_{\max }$ were not significantly different between the groups, but bending moments for fracture were higher for the straight relative to the angled abutments. Such a result was not expected considering the differences in the lever scenario created for both groups, but may be accounted by the difference in the moment of inertia between the two designs.

The resulting failure modes where the straight abutments showed fractures at the cervical region compared to fractures at the point of load application in the angled abutments likely reflected the resulting bending moments for both groups. From a clinical standpoint, although both scenarios may fail at similar time points, it can be speculated that in a restoration supported by a thinned angled zirconia abutment, the crown is more likely to shield the functional area receiving the load compared to a thinned straight abutment. Such an assumption warrants further investigation. The bending moments of both groups were significantly higher compared to values observed in the literature ${ }^{18}$. This could be related to the double zirconia/titanium anchorage system.

As to the testing methods available for the evaluation of different implant-abutment system configurations, several have been described, such as the single load to fracture ${ }^{1}$, the use of fatigue followed by the application of a static load until fracture ${ }^{5,11}$, the staircase method ${ }^{16}$, fatigue limit (ISO 14801:2007), step-stress accelerated life testing $^{6}$, and others. While the ISO 14801 was created in 2003 and revised in 2007, with the aim of standardizing the testing procedures and data presentation in the fatigue of dental implants, it has been shown that the results produced by such a method should be interpreted with caution. The wide range of testing parameters allowed in the ISO 14801:2007 regarding the testing frequency ( 2 to $15 \mathrm{~Hz}$ ), environment (water or dry when testing above $15 \mathrm{~Hz}$ ) and amount of cycles (2 or 5 million, depending on the chosen frequency) have shown that a very different failure probability distribution may result ${ }^{10}$, as well as failure modes ${ }^{12}$. Whereas, the present study utilized the highest end of the speed scale allowed by the norm, especially to optimize the machine testing time, potential differences in the fatigue limit and failure modes when testing in $2 \mathrm{~Hz}$ in water may exist and warrant future investigation. It may be suggested that, while attending industry requirements for implants quality assurance and control, the ISO 14801:2007 testing methodology may likely continue to be developed 
as observed from 2003 to the currently advocated version $^{10,12}$.

As generally reported and also in agreement with our testing results, the discrepancy in values arising from the static relative to the dynamic testing and the clinical relevance of each, should be acknowledged. If the selection of a system was based on the static test results, which do not simulate physiological loading scenarios where repetitive, lower load cycling is the chief mechanism leading to failure, most systems would be suitable irrespective of the area of application (molar or incisor). With static loading, materials will commonly fail at loads higher than those in fatigue. The mechanisms of subcritical crack growth that should be simulated in testing include those that operate in use-related failures which are stress corrosion and cyclic fatigue $^{14}$. In this study, static testing was only performed to provide load values for subsequent fatigue testing. Fatigue can provide more effective ways of simulating failures observed clinically ${ }^{4}$.

Considering that the reported maximal bite force in the incisor area may vary from $108 \mathrm{~N}^{8}$ to $190 \mathrm{~N}^{7,9}$, the $F_{\text {max }}$ fatigue loads observed for both thin-walled straight or angled zirconia abutments are above the physiologic range. Therefore, in esthetically demanding areas, zirconia abutments may be indicated especially when thin peri-implant soft tissues are present ${ }^{19}$. Although no direct comparison was performed with titanium abutments, shortterm clinical studies and systematic reviews point toward similar success rates for both materials and no influence in the failure behavior of the overlying restorative system ${ }^{9}$. Future long-term clinical studies are warranted.

\section{CONCLUSION}

The postulated null hypothesis that a straight bi-component abutment would not present different $\mathrm{F}_{\max }$ than an angled abutment under fatigue was accepted. However, failure modes differed between the groups.

\section{ACKNOWLEDGEMENTS}

The authors do not have any financial interest, either directly or indirectly, in the products listed in the study. We highly appreciated the skills and commitment of Eng. Enrico Babetto for the technical support and Dr. Audrenn Gautier and Dr. Henry Canullo in the supervision of the study.

\section{REFERENCES}

1- Al-Omari WM, Shadid R, Abu-Naba'a L, El Masoud B. Porcelain fracture resistance of screw-retained, cement-retained, and screw-cement-retained implant-supported metal ceramic posterior crowns. J Prosthodont. 2010;19:263-73.
2- Canullo L. Clinical outcome study of customized zirconia abutments for single-implant restorations. Int J Prosthodont. 2007;20:489-93.

3- Canullo L, Morgia P, Marinotti F. Preliminary laboratory evaluation of bicomponent customized zirconia abutments. Int J Prosthodont. 2007;20:486-8.

4- Coelho PG, Bonfante EA, Silva NR, Rekow ED, Thompson VP. Laboratory simulation of Y-TZP all-ceramic crown clinical failures. J Dent Res. 2009;88:382-6.

5- Dittmer MP, Dittmer S, Borchers L, Kohorst P, Stiesch M. Influence of the interface design on the yield force of the implantabutment complex before and after cyclic mechanical loading. J Prosthodont Res. 2012;56:19-24.

6- Freitas AC Jr, Bonfante EA, Rocha EP, Silva NR, Marotta L, Coelho PG. Effect of implant connection and restoration design (screwed vs. cemented) in reliability and failure modes of anterior crowns. Eur J Oral Sci. 2011;119:323-30.

7- Hagberg C. Assessment of bite force: a review. J Craniomandib Disord. 1987; 1:162-9.

8- Helkimo E, Carlsson GE, Helkimo M. Bite force and state of dentition. Acta Odontol Scand. 1977;35:297-303.

9- Helkimo $E$, Ingervall B. Bite force and functional state of the masticatory system in young men. Swed Dent J. 1978;2:167-75. 10- Karl M, Kelly JR. Influence of loading frequency on implant failure under cyclic fatigue conditions. Dent Mater. 2009;25:142632.

11- Kohal RJ, Wolkewitz M, Tsakona A. The effects of cyclic loading and preparation on the fracture strength of zirconiumdioxide implants: an in vitro investigation. Clin Oral Implants Res. 2011;22:808-14.

12- Lee CK, Karl M, Kelly JR. Evaluation of test protocol variables for dental implant fatigue research. Dent Mater. 2009;25:1419-25. 13- Marchack CB. A custom titanium abutment for the anterior single-tooth implant. J Prosthet Dent. 1996;76:288-91.

14- Paris $P$, Erdogan F. A critical analysis of crack propagation laws. J Basic Eng. 1963;85:528-34.

15- Priest G. Single-tooth implants and their role in preserving remaining teeth: a 10-year survival study. Int J Oral Maxillofac Implants. 1999; 14:181-8.

16- Ribeiro CG, Maia ML, Scherrer SS, Cardoso AC, Wiskott HW. Resistance of three implant-abutment interfaces to fatigue testing. J Appl Oral Sci. 2011;19:413-20.

17- Sailer I, Philipp A, Zembic A, Pjetursson BE, Hämmerle $\mathrm{CH}$, Zwahlen $\mathrm{M}$. A systematic review of the performance of ceramic and metal implant abutments supporting fixed implant reconstructions. Clin Oral Implants Res. 2009;20:4-31.

18- Sailer I, Sailer T, Stawarczyk B, Jung RE, Hämmerle $\mathrm{CH}$. In vitro study of the influence of the type of connection on the fracture load of zirconia abutments with internal and external implant-abutment connections. Int J Oral Maxillofac Implants. 2009;24:850-8.

19- Sailer I, Zembic A, Jung RE, Hämmerle CH, Mattiola A. Singletooth implant reconstructions: esthetic factors influencing the decision between titanium and zirconia abutments in anterior regions. Eur J Esthet Dent. 2007;2:296-310.

20- Scholander S. A retrospective evaluation of 259 single-tooth replacements by the use of Brånemark implants. Int ] Prosthodont. 1999; 12:483-91.

21- Wannfors K, Smedberg JI. A prospective clinical evaluation of different single-tooth restoration designs on osseointegrated implants. A 3-year follow-up of Brånemark implants. Clin Oral Implants Res. 1999;10:453-8.

22- Zembic A, Sailer I, Jung RE, Hämmerle $\mathrm{CH}$. Randomizedcontrolled clinical trial of customized zirconia and titanium implant abutments for single-tooth implants in canine and posterior regions: 3-year results. Clin Oral Implants Res. 2009;20:802-8. 